Originally published in: Journal of Experimental Psychology: Learning, Memory, and Cognition vol. 41 (2015) no. 6, pp. $1648-1662$. DOI: https://doi.org/10.1037/xlm0000128

(C)American Psychological Association, [2015]. This paper is not the copy of record and may not exactly replicate the authoritative document published in the APA journal. Please do not copy or cite without author's permission. The final article is available at: https://doi.org/10.1037/xlm0000128.

\section{POSTPRINT}

\author{
Franziska Kretzschmar \\ Johannes Gutenberg University of Mainz and Philipps University of Marburg \\ Matthias Schlesewsky \\ Johannes Gutenberg University of Mainz and University of South Australia, Adelaide \\ Adrian Staub \\ University of Massachusetts, Amherst
}

\title{
Dissociating Word Frequency and Predictability Effects in Reading: Evidence From Coregistration of Eye Movements and EEG
}

\begin{abstract}
Two very reliable influences on eye fixation durations in reading are word frequency, as measured by corpus counts, and word predictability, as measured by cloze norming. Several studies have reported strictly additive effects of these 2 variables. Predictability also reliably influences the amplitude of the N400 component in event-related potential studies. However, previous research suggests that while frequency affects the N400 in single-word tasks, it may have little or no effect on the N400 when a word is presented with a preceding sentence context. The present study assessed this apparent dissociation between the results from the 2 methods using a coregistration paradigm in which the frequency and predictability of a target word were manipulated while readers' eye movements and electroencephalograms were simultaneously recorded. We replicated the pattern of significant, and additive, effects of the 2 manipulations on eye fixation durations. We also replicated the predictability effect on the N400, time-locked to the onset of the reader's first fixation on the target word. However, there was no indication of a frequency effect in the electroencephalogram record. We suggest that this pattern has implications both for the interpretation of the N400 and for the interpretation of frequency and predictability effects in language comprehension.
\end{abstract}

Keywords: eye movements, fixation-related potentials, N400, word frequency, word predictability

Word frequency and predictability are considered important determinants of how quickly listeners and readers can access the meaning of a word and integrate it into a sentence or discourse context. While research on spoken word recognition has centered on the question of when predictability exerts a measurable influence in the processing of continuous speech (dating back to, e.g., Marslen-Wilson, 1987; Zwitserlood, 1989), a considerable number of studies on written language comprehension have in addition

Franziska Kretzschmar, Department of English and Linguistics, Johannes Gutenberg University of Mainz, and Department of Germanic Linguistics, Philipps University of Marburg; Matthias Schlesewsky, Department of English and Linguistics, Johannes Gutenberg University of Mainz, and School of Psychology, Social Work, and Social Policy, University of South Australia, Adelaide; Adrian Staub, Department of Psychological and Brain Sciences, University of Massachusetts, Amherst.

This research was carried out while Franziska Kretzschmar was a visiting scholar at the University of Massachusetts. The research stay was supported by Grant SCHL544/6-1 awarded to Matthias Schlesewsky by the German Research Foundation (DFG). We thank Torsten Schenk for help with software implementation and Carm DeMaio, Jessica Garbec, Julian Jarosch, Anne Lee, and Aujan Mehregan for help with data acquisition and preparation.

Correspondence concerning this article should be addressed to Franziska Kretzschmar, Department of English and Linguistics, General Linguistics, Johannes Gutenberg University of Mainz, Jakob-Welder-Weg 18, 55128 Mainz, Germany. E-mail: kretzsc@uni-mainz.de focused on the relative and independent contribution of frequency in word recognition. Part of this interest has stemmed from the observation that different experimental methods provided contradictory results and, hence, different interpretations of the interplay of word frequency and predictability. For instance, when readers' eye movements are monitored, frequency contributes to word recognition independently from predictability; that is, the two factors have strictly additive effects on fixation durations (e.g., Kennedy, Pynte, Murray, \& Paul, 2013; Rayner, Ashby, Pollatsek, $\&$ Reichle, 2004). In these cases, fixation times are increased when a word is low in frequency or unpredictable. Contrary to this, electrophysiological recordings have revealed that the amplitude of the N400, an endogenous component of the human electroencephalogram (EEG) that is sensitive to semantic processing (Kutas \& Federmeier, 2011), is reliably modulated by word frequency only for words embedded in word lists or at the beginning of a sentence. Frequency either does not affect the N400 at all when a target word occurs following substantial sentence context (Van Petten \& Kutas, 1990), or its influence is substantially reduced in later sentence positions (Dambacher, Kliegl, Hofmann, \& Jacobs, 2006).

It is at present a puzzle that word frequency has a significant effect on fixation durations in all normal reading contexts but that the N400 correlate of a frequency effect may be absent when a word is presented with a preceding sentence context. As both eye movements in reading and electrophysiological recordings via event-related potentials (ERPs) are considered to exhibit a high 
sensitivity to online processes in language comprehension (Kutas, Van Petten, \& Kluender, 2006; Sereno \& Rayner, 2003), the aim of the current study is to investigate whether word frequency and predictability indeed affect eye movements and ERPs differently by means of concurrent EEG-eye movement recordings. This design addresses the question of whether a dissociation between the effects of word frequency and predictability in the eye movement and ERP records remains in evidence when the two types of recordings are based on the very same experimental trials.

Possible explanations for the discrepancy between the two methods can be narrowed down to two general claims. First, differences in stimulus presentation method may be crucial. The relevant ERP studies in the visual domain have used rapid serial visual presentation (RSVP), in which words are presented one at a time in central vision with a fixed presentation rate determined by the experimenter. From a temporal perspective, visual information uptake with RSVP is thus similar to auditory presentation in enforcing serial information uptake. However, natural reading provides a parafoveal preview of upcoming words, which allows partial parallel information uptake (Rayner \& Clifton, 2009). RSVP rates are also rather slow compared to typical reading rates of initial processing such as single fixation or first fixation durations. In addition, the interstimulus interval (ISI) is usually longer than the average saccade duration between two fixations. Finally, with RSVP, readers are not able to make a regression to previously read parts of a sentence when they face severe comprehension difficulties. It is thus possible that the effects of word frequency and predictability on the N400 would more closely reflect the eye movement data (i.e., with additive effects of both variables) if ERPs were collected in a more natural reading situation.

Second, it is possible that the reliable frequency effect observed in fixation durations does not appear in the N400 because the two measures actually do reflect different underlying processes. The N400 is not modality specific, occurring with both visual and auditory stimulus presentation (Kutas \& Federmeier, 2011). Thus, it appears likely that this ERP component reflects modalityindependent aspects of language processing. Word frequency, however, may play an especially important role in the control of eye movements in reading. This variable is given an important status in models of eye movement control in reading such as E-Z Reader (Reichle, Pollatsek, Fisher, \& Rayner, 1998; Reichle, Rayner, \& Pollatsek, 2003) and SWIFT (Engbert, Nuthmann, Richter, \& Kliegl, 2005), with word frequency being a primary determinant, in both models, of when a saccade is initiated to leave the currently fixated word. In sum, the discrepancy between fixation duration and ERP measures, with respect to the influence of word frequency, may be due to the fact that frequency has a major influence on eye movement control in reading in addition to whatever influence it may have on the modality-independent processes reflected in the N400.

The remainder of the paper is organized as follows. In the next two sections, we briefly review existing findings relating to the effects of word frequency and predictability on eye movements in reading and on neuronal activity as measured in the N400 component. We then describe the present experiment, which replicates the methodical difference for the effect of word frequency in context. In the discussion, we address the two aforementioned explanations in light of the current findings.

\section{Word Frequency and Predictability Independently Affect Eye Movement Control}

Many studies have demonstrated frequency (e.g., Inhoff \& Rayner, 1986; Rayner \& Duffy, 1986; Staub, White, Drieghe, Hollway, \& Rayner, 2010) and predictability (e.g., Ehrlich \& Rayner, 1981; Staub, 2011) effects on eye movements in reading. These factors influence both the first fixation duration and gaze duration (i.e., the sum of all first-pass fixation durations) measures, with low-frequency or unpredictable words eliciting longer reading times than higher-frequency or predictable words. There is evidence that these factors also influence the even earlier measure of skipping probability (e.g., Drieghe, Rayner, \& Pollatsek, 2005; Reichle \& Drieghe, 2013), as a high-frequency or predictable word is more likely to be skipped without being fixated directly; it appears that the effect of predictability on the skipping rate may be larger than the effect of frequency. Thus, both factors influence early stages of processing a word during normal reading. There is, however, evidence of subtle differences between these effects. Analyses of fixation duration distributions have shown that while frequency influences both the location of the distribution of fixation durations and the weight of the distribution's right tail (Reingold, Reichle, Glaholt, \& Sheridan, 2012; Staub et al., 2010), predictability influences only the former of these two distributional parameters (Sheridan \& Reingold, 2012; Staub, 2011; Staub \& Benatar, 2013).

The question of whether these effects interact statistically has been addressed repeatedly in the literature. The answer to this question influences how these variables are treated in implemented models of eye movement control in reading such as E-Z Reader (Reichle et al., 2003) and SWIFT (Engbert et al., 2005) and is relevant to the broader issue of whether the two factors influence common or distinct processing stages in reading and in language processing more generally. An intuitive prediction, which is made explicit in models that attribute the frequency effect itself to differential expectations for encountering low- and high-frequency words (e.g., Levy, 2008; McDonald \& Shillcock, 2003; Norris, 2006), is that the predictability effect should be larger for lowfrequency words than for high-frequency words. If a lowfrequency word is difficult to process in a single-word task, or in a neutral context, in part because the reader does not expect to encounter such a word, then putting a low-frequency word in a context in which it is highly expected should ease its processing substantially. On the other hand, the benefit to a high-frequency word of appearing in a predictive context should be less pronounced, because a high-frequency word is relatively likely a priori.

In fact, a fairly large number of eye movement studies have factorially manipulated the frequency and predictability of target words, and while these studies have obtained robust reading time effects of each variable when both are manipulated, they have not obtained any evidence of a statistical interaction (Altarriba, Kroll, Sholl, \& Rayner, 1996; Ashby, Rayner, \& Clifton, 2005; Bélanger \& Rayner, 2013; Gollan et al., 2011; Hand, Miellet, O’Donnell, \& Sereno, 2010; Rayner et al., 2004). Several studies evaluating frequency and predictability effects in eye movement corpora (Kennedy et al., 2013; Miellet, Sparrow, \& Sereno, 2007; Kliegl, Grabner, Rolfs, \& Engbert, 2004; Whitford \& Titone, 2014) have also found only additive effects of these two variables on early 
reading time measures. Finally, Staub (2011; Staub \& Benatar, 2013; see also Slattery, Staub, \& Rayner, 2012) examined the effect of predictability on fixation durations using a design in which each subject read a large number of target words twice, in high- and low-predictability contexts, where word frequency ranged continuously from very high to relatively low. Again, these studies found robust effects of both variables without a statistically significant interaction.

It is notable, in assessing these results, that not only are there no reports of statistical interactions (which, given the number of studies, might be expected to occur based on the Type I error rate alone), but also that there is not even a consistent trend. While some studies do show a trend toward the interaction suggested above, with a larger predictability effect appearing for lowfrequency words (e.g., Altarriba et al., 1996; Rayner et al., 2004), an approximately equal number show a trend in the opposite direction, with a larger predictability effect appearing for highfrequency words (e.g., Gollan et al., 2011; Staub, 2011). Thus, a comparison of results across studies does not support the conclusion that the failure to obtain a significant interaction in individual studies is due to a lack of statistical power. Moreover, while a few studies have reported an interactive effect of frequency and predictability on skipping rate (Gollan et al., 2011; Rayner et al., 2004), these have been opposing effects in different studies, with Rayner et al. (2004) reporting a larger effect of predictability on skipping rate for high-frequency words and Gollan et al. (2011) reporting a larger effect of predictability for low-frequency words. Most studies have not reported a significant interaction in either direction.

In sum, the repeated failure to obtain interactive effects of frequency and predictability seems to provide fairly strong evidence in favor of the null hypothesis that these variables have additive, noninteractive effects on eye movements. (For discussion of the general theoretical importance of establishing null interactions in psychology, see, e.g., Gallistel, 2009.)

\section{Predictability Outranks Word Frequency in Affecting the N400 Component}

It has long been recognized that expected words exhibit a reduced N400, which is reflected in the well-known inverse relationship between N400 amplitude and cloze probability. This processing advantage for predicted words can be induced by lexical associates, by contextual cues in the absence of lexical association (e.g., Connolly \& Phillips, 1994; DeLong, Urbach, \& Kutas, 2005; Federmeier \& Kutas, 1999; Frank, Otten, Galli, \& Vigliocco, 2015; Kutas \& Hillyard, 1980, 1984; Laszlo \& Federmeier, 2009; Roehm, Bornkessel-Schlesewsky, Rösler, \& Schlesewsky, 2007; Van Petten, Coulson, Rubin, Plante, \& Parks, 1999; Van Petten \& Kutas, 1990; Vissers, Chwilla, \& Kolk, 2006), and by more global pragmatic cues (e.g., Van Berkum, Hagoort, \& Brown, 1999). ${ }^{1}$

There is also clear evidence that word frequency influences the N400 amplitude so that it is enhanced for low-frequency compared to high-frequency words. However, the frequency effect appears to be modified by contextual parameters. While robust frequency modulations emerge for words presented in lists (e.g., Barber, Vergara, \& Carreiras, 2004; Condray, Siegle, Keshavan, \& Steinhauer, 2010; Grainger, Lopez, Eddy, Dufau, \& Holcomb, 2012;
Hauk \& Pulvermüller, 2004; Lehtonen et al., 2012; Münte et al., 2001; Rugg, 1990), frequency appears to reliably affect N400 amplitude only for content words at the beginning of a sentence, not at later positions. For instance, Van Petten and Kutas (1990) found a general trend for the mean amplitude of the N400 to decrease as the sentence unfolded (see also Osterhout, Bersick, \& McKinnon, 1997, who found that N400 amplitude for open-class words was reduced for normal prose compared with scrambled, i.e., context-free, prose). They found that the N400 frequency effect was absent altogether for words occurring late in a semantically coherent sentence, leading the authors to conclude that sufficiently rich contextual information can override frequency information (see also Van Petten \& Kutas, 1991, and for converging findings from magnetoencephalography, Halgren et al., 2002). This finding of a diminishing frequency effect with increasing amounts of preceding context was later corroborated in studies looking at frequency alone or at the interaction of frequency and predictability (cf. Brown, Hagoort, \& ter Keurs, 1999; Penolazzi, Hauk, \& Pulvermüller, 2007; Van Petten, Kutas, Kluender, Mitchiner, \& McIsaac, 1991).

Recently, a couple of studies aimed at investigating these variables under more reading-like situations. Dambacher et al. (2006) collected ERPs from words in the Potsdam Sentence Corpus, which consists of 144 single sentences of various syntactic structures (cf. Kliegl et al., 2004), and ran a range of regression models on the resulting data. They found a significant interaction between frequency and predictability, with the benefit of predictability being stronger for low-frequency words. The main effect of frequency, by contrast, was only significant when the interaction was removed as a predictor from the regression models and was much smaller in later sentence positions. It is notable that the very same corpus had previously shown reliable main effects of frequency and predictability for readers' eye movements (Kliegl et al., 2004; Kliegl, Nuthmann, \& Engbert, 2006). In a later study, Dambacher and colleagues used target words extracted from the same corpus in an experimental design, in which word frequency and predictability were orthogonally manipulated, and had three groups of participants read sentences for comprehension (Dambacher et al., 2012). Their goal was to elucidate whether the stimulus onset asynchrony (SOA) might account for the discrepancy between ERPs and eye movement results. In three RSVP experiments with SOAs of 700,490 , and $280 \mathrm{~ms}$, the authors found neither the interaction nor a main effect of word frequency on the N400. Thus, even a more reading-like stimulus presentation rate does not appear to induce reliable frequency effects on the N400 in RSVP settings.

Together, these findings illustrate the lack of reliability of frequency effects on the N400 when words are presented in sentence context and illustrate the role of sentence position. Indeed, it is not clear that there is any frequency effect at all on N400 amplitude when a word occurs relatively late in a sentence, even when its overall predictability is low. Importantly, these findings also hold in RSVP experiments with shorter SOAs that induce a faster

\footnotetext{
${ }^{1}$ Note, however, that this seems to hold for words whose cloze probability is smaller than 1 . In cases of perfect predictability, target words do not elicit an N400 but rather a P300 (cf. Kutas \& Hillyard, 1984; Molinaro \& Carreiras, 2010; Roehm, Bornkessel-Schlesewsky, Rösler, \& Schlesewsky, 2007)
} 
presentation rate comparable to normal reading. In simple word lists, by contrast, frequency remains a strong predictor of N400 activity, as predictability (if not induced via a secondary task) is not operative outside of a sentence context.

\section{The Present Study}

In the previous two sections, we have reviewed research from separate ERP and eye movement experiments suggesting that (a) predictability reliably influences both fixation durations and N400 amplitudes and (b) the effect of word frequency on fixation durations is equally reliable (and additive with the effect of predictability), but that (c) the effect of word frequency on N400 amplitudes may be absent altogether when a word appears with a substantial preceding sentence context. In addition, SOA in the RSVP task appears not to account for these diverging findings with regard to the independent influence of frequency. However, no previous study has tested directly whether natural reading exhibits different processing characteristics.

In the present study, we orthogonally varied frequency and predictability for target words embedded in single sentences and had participants read for comprehension while both their eye movements and brain activity were recorded simultaneously. Notably, our target words appeared relatively late in the critical sentences, at a point at which the frequency effect on the N400 has been found to be absent. Based on the existing literature, we expected to replicate the additive effects of word frequency and predictability in the eye movement record. We also expected predictability to influence the N400, time-locked to the first fixation on the target word; this timing of the predictability effect on the N400 in natural reading has previously been reported by Dimigen, Sommer, Hohlfeld, Jacobs, and Kliegl (2011), who also recorded EEGs and eye movements simultaneously. Note that Kretzschmar, Bornkessel-Schlesewsky, and Schlesewsky (2009) also reported a predictability effect on the parafoveal N400, but this study involved perfectly constraining contexts with very uniform sentence structure involving antonyms-for example, black is the opposite of white. This design thus differs from the present predictability manipulation, which included a range of different predictability scores and varied sentence structure. The critical question was whether a word frequency effect (or its interaction with predictability) on the N400 related to the first fixation would also emerge in the present experiment.

\section{Method}

\section{Participants}

Thirty-eight students (25 female, mean age: 20.3 years, range 18-29) from the University of Massachusetts (UMass) Amherst student population participated in the experiment for course credit. They were right-handed as assessed by a modified version of the Edinburgh handedness test (Oldfield, 1971), and none of them reported neurological or psychological disorders. All participants were raised monolingually and had normal or corrected-to-normal vision. Data from six additional participants were not analyzed due to technical problems during data acquisition, reports of psychological disorders, or because they did not properly read the stimuli.

\section{Materials}

We selected 40 high-frequency $(M=123.93, S D=127.22$, minimum $=19.12$, maximum $=509.37$; word length $M=5.37$, $S D=1.14$, minimum $=4$, maximum $=8)$ and 40 low-frequency words $(M=2.05, S D=1.51$, minimum $=0$, maximum $=4.69$; word length $M=5.63, S D=1.12$, minimum $=4$, maximum $=8$ ) as target words in the experiment. Each word was embedded in both a high-predictability and a low-predictability context. Raw word frequencies were calculated as counts per million from the SUBTLEX corpus (Balota et al., 2007; see also Brysbaert \& New, 2009), and frequency differed reliably between the two groups (Wilcoxon's rank sum test $\mathrm{W}=1,600, p<.001$ ). Word length did not differ between conditions, $t(77.97)=1.04, p<.1$. Table 1 gives example stimuli for each critical condition.

Predictability scores were collected by means of separate cloze norms. For all but five of the low-frequency words, each of the contexts up to, but not including, the target word was provided to between 34 and 38 members of the UMass student population who did not participate in the main experiment. Each subject completed only one of the two contexts for each word. They were asked to write the word that seemed most likely to come next in the sentence. The remaining five low-frequency words were normed with 10 subjects per context. Table 2 gives the mean predictability scores in each condition. Predictability differed significantly between the low- and high-predictability conditions for both frequency classes (for each comparison: Wilcoxon's rank sum test $\mathrm{W}=1,600, p<.001)$. In all four conditions, the mean position of the target word in the sentence was between nine and 11 words from the beginning. The means and standard deviations in each condition are given in Table 2 . Predictable words occurred slightly later in the sentence than did unpredictable words, $F(1,78)=$ $12.55, p<.001$. Frequency did not significantly influence sentence position, $F(1,78)=1.78, p<.2$, nor was there a significant effect of the interaction between frequency and predictability $(F<1)$.

Four lists were created from the 160 critical sentences so that each subject would see 40 sentences in each of the four conditions. The 160 critical sentences were interspersed with 30 unrelated filler sentences from another experiment and presented in four

Table 1

Example Stimuli

\begin{tabular}{ll}
\hline \multicolumn{1}{c}{ Condition } & \multicolumn{1}{c}{ Example } \\
\hline Low frequency-high predictability & The extremely skinny model looked like she suffered from anorexia and a lack of sleep. \\
Low frequency-low predictability & I want to go to graduate school so I can help people with anorexia recover from their illness. \\
High frequency-high predictability & On Sunday morning, the nun went to pray at the church and then went for a walk. \\
High frequency-low predictability & Yesterday I noticed that we passed by a church on our way to the apartment. \\
\hline
\end{tabular}

Note. Target words are underlined. 
Table 2

Mean Cloze Probability and Mean Sentence Position per Condition

\begin{tabular}{lcc}
\hline \multicolumn{1}{c}{ Condition } & Cloze probability & Sentence position \\
\hline Low frequency-high predictability & $0.73(0.18)$ & $10.68(2.56)$ \\
Low frequency-low predictability & $0.00(0.01)$ & $10.13(2.60)$ \\
High frequency-high predictability & $0.84(0.13)$ & $10.15(2.91)$ \\
High frequency-low predictability & $0.01(0.03)$ & $9.18(2.52)$ \\
\hline
\end{tabular}

Note. Sentence position is counted in words. Standard deviations are given in parentheses.

different pseudorandomized orders. To keep participants focused on reading for comprehension, simple yes/no comprehension questions followed $1 / 8$ of the critical sentences (and 1/3 for filler sentences). The overall accuracy for questions related to critical stimuli was $91 \%$. (Three subjects actually showed accuracy of $20 \%$ or below, which we attribute to reversing the response buttons. These subjects' responses were reversed for the computation of overall accuracy.)

\section{Apparatus and Procedure}

The EEG was recorded from $23 \mathrm{Ag} / \mathrm{AgCl}$ electrodes fixed on the scalp by means of an elastic cap (EasyCap, Herrsching, Germany) according to the International 10/20 system. The ground electrode was placed at AFz. Data were referenced to the left mastoid online but rereferenced to both mastoids offline. The electrooculugram (EOG) was monitored with six electrodes placed at the outer canthi of the eyes and above and below both eyes. All impedances were kept below $5 \mathrm{k} \Omega$. The data were amplified with a BrainAmp amplifier (Brain Products, Gilching, Germany) with a $500-\mathrm{Hz}$ sampling rate. Eye movements were registered with an EyeLink 1000 (SR Research Ltd., Ontario, Canada) sampling at $1,000 \mathrm{~Hz}$. Viewing was binocular, but only the right eye was monitored. Both systems were synchronized online by transistortransistor-logic (TTL) pulses sent to both recording machines at various times during each trial, but actual fixation-related triggers for the EEG were computed offline (see below).

Custom in-house software presented the stimuli on a CRT monitor (Iiyama Corp., Tokyo, Japan) in black on a white background. Sentences were presented in Courier New font with a size of 14 points, resulting in approximately three letters per degree of visual angle.

After giving written consent, participants were familiarized with the procedure via written instructions and began the experimental session with a short practice period comprising eight sentences. All experimental sentences were then presented in five blocks with short breaks in between and when requested by the subject. Each trial began with a small black square at the left edge of the display, which served as an automatic trigger for sentence presentation. Sentences were only presented after a valid fixation had been registered on the square. Participants were instructed to press a button once they had finished reading the sentence. A drift correction check was performed before each trial, and calibration was repeated after breaks and when necessary. Participants were told explicitly to read for comprehension, as there would be comprehension questions after some of the sentences, and answering them accurately was important. Including electrode preparation, a session lasted about $2 \mathrm{hr}$.

\section{Analysis}

Before statistical analysis, the eyetracking record for each participant was screened for erroneous fixations, blinks, and very short or long fixations (less than $80 \mathrm{~ms}$ or more than $800 \mathrm{~ms}$ ). Trials in which blinks or long fixations $(>800 \mathrm{~ms})$ were registered on the target were discarded from further analysis and were not used to synchronize the EEG and eyetracking records. In the next step, fixation-related triggers for the EEG data were computed based on the eyetracking record and the random TTL pulses that were sent during data acquisition. The raw EEG data were filtered using a $0.3-$ to $20-\mathrm{Hz}$ bandpass filter and underwent an automatic artifact rejection to remove excessive artifacts due to ocular movements or amplifier saturation (rejection threshold of $40 \mu \mathrm{V}$ ). Then, average fixation-related potentials (FRPs) were computed per condition per subject from $-200 \mathrm{~ms}$ before fixation onset to 1,200 ms after fixation onset. Grand averages were subsequently computed based on single-subject averages. For the FRPs, repeated-measures analyses of variance (ANOVAs) were computed for successive 50-ms time windows involving the factors FREQUENCY (high vs. low), PREDICTABILITY (predictable vs. unpredictable), and the topographical factor region of interest (ROI). Since we focus on the N400 component that has a posterior maximum, the factor ROI was restricted to centro-parietal electrodes in both hemispheres, because these sites are least affected by ocular artifacts (cf. Picton et al., 2000). Lateral ROIs had four levels (left centro-parietal: CP5 $\mathrm{CP} 1$, right centro-parietal: $\mathrm{CP} 6 \mathrm{CP}$, left parietal: $\mathrm{P} 7 \mathrm{P} 3$, right parietal: $\mathrm{P} 8 \mathrm{P} 4)$, and midline sites had two levels ( $\mathrm{CPz}$ and $\mathrm{Pz})$. For analyses involving more than one degree of freedom in the numerator, alpha was corrected for sphericity violations following Huynh and Feldt (1970). Effects were only considered significant if, for a given effect, $p$ was less than .05 in two consecutive time windows (Gunter, Friederici, \& Schriefers, 2000). Follow-up pairwise comparisons were tested only when interaction effects were significant $(p<.05)$

Fixation durations were analyzed with repeated-measures ANOVAs using R statistical software (the R Foundation for Statistical Computing, 2013). Fixed factors were FREQUENCY and PREDICTABILITY, and subjects and items were treated as random factors $F_{1}$ and $F_{2}$, respectively. For fixational measures, we report analyses for the first fixation, gaze duration, and prior fixation duration; first-pass regressions and skipping rates were also analyzed to investigate possible effects in saccadic measures (cf. Word Frequency and Predictability Independently Affect Eye Movement Control above) using ANOVA over empirical logittransformed proportions (e.g., Barr, 2008).

\section{Results}

\section{Fixation-Related Potentials (FRPs)}

Figure 1 shows FRPs time-locked to the onset of the first fixation on the target word. Visual inspection suggests that an early positivity (P200) peaking around $180 \mathrm{~ms}$ post fixation onset, and an ensuing broad negativity (N400) with a peak at approximately $300 \mathrm{~ms}$ post fixation onset, were both influenced by predictability. 


\section{First Fixation-related Potentials}
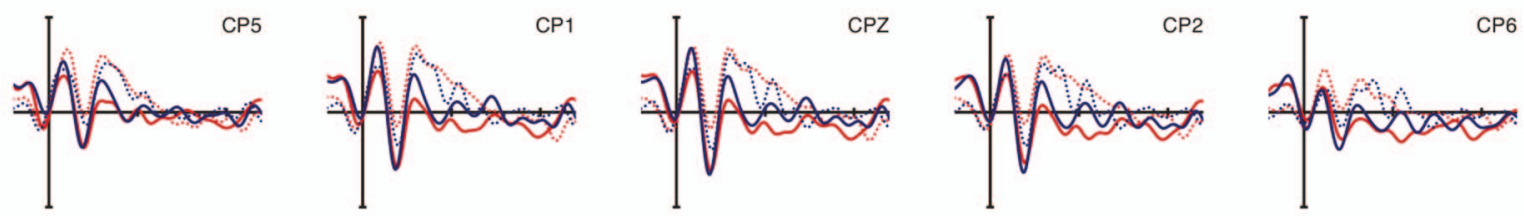

CP6
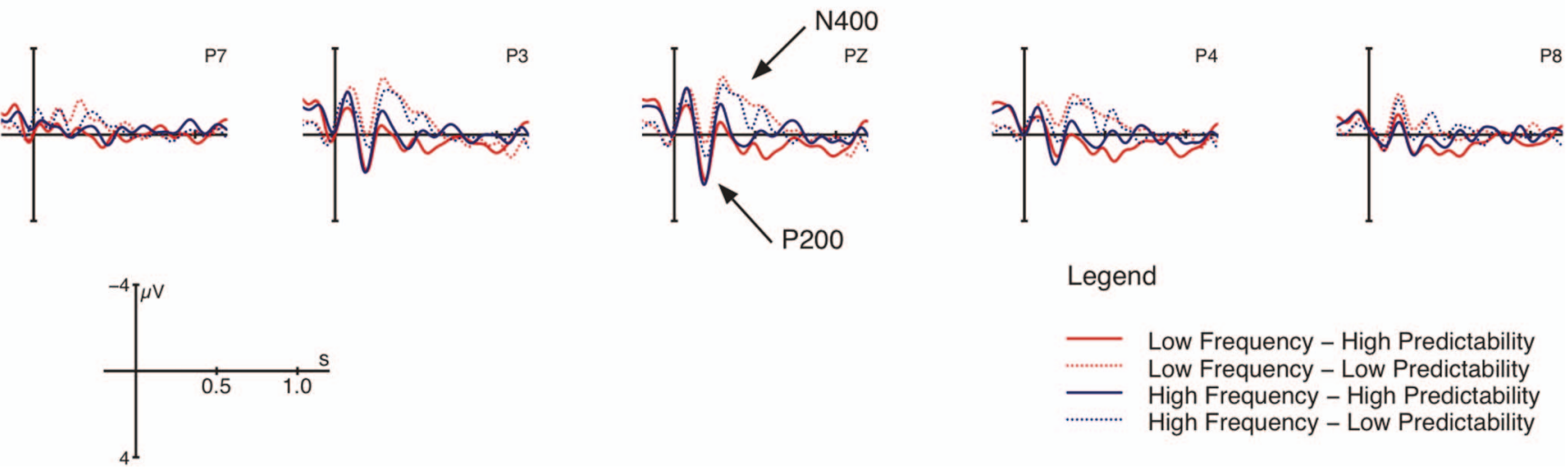

Legend

Figure 1. Grand average fixation-related potentials (FRP) time-locked to the onset of the first fixation on the target word (vertical bar). Negativity is plotted upward. FRPs were smoothed with an 8-Hz low-pass filter for visual presentation only. See the online article for the color version of this figure.

The statistical tests summarized in Table 3 confirm these impressions. As can be seen, predictability influenced FRP amplitude starting in the 150- to 200-ms window. This main effect of predictability also greatly influenced the N400 amplitude, with predictable words showing a reduced N400 (cf. Figure 2, Panel A). This effect lasted for the entire N400 time window and somewhat beyond - that is, up to $650 \mathrm{~ms}$ after fixation onset. In addition, we also found a hint of an interaction between frequency and predictability between 300 and 350 $\mathrm{ms}$ at the lateral electrode sides which, however, failed significance tests in two consecutive time windows. Contrasting with the strong impact of predictability, word frequency alone did not influence any of the FRP components time-locked to the first fixation on the target (cf. Figure 2, Panel B). Although there was an interaction between frequency and ROI in the time window from 250 to $300 \mathrm{~ms}$ post fixation onset, the resolution by ROI yielded no further significant effects of frequency in any of the lateral or midline ROIs.

As previous research has found that parafoveal processing of upcoming words is reflected well before $300 \mathrm{~ms}$ after fixation onset (e.g., Baccino \& Manunta, 2005; Simola, Holmqvist, \& Lindgren, 2009) and that component latencies found for the first fixation-related FRPs also hold for the prior fixation (Kretzschmar et al., 2009), we investigated parafoveal processing from 150 up to $400 \mathrm{~ms}$ after the onset of the fixation immediately preceding the first fixation on the target. Later time windows are likely to be contaminated by activity evoked by first fixation-related processing.

Figure 3 shows FRPs time-locked to the onset of the prior fixation before readers first fixated the target. Up to around $350 \mathrm{~ms}$, FRP waves do not diverge significantly, except for the P200 time window, which also showed differential activity during the first fixation. There- fore, statistical tests, as shown in Table 4, were carried out from 150 $\mathrm{ms}$ to $400 \mathrm{~ms}$ post fixation onset.

Although predictability seemed to exert some influence on the P200, these impressions were not confirmed statistically. The effect of predictability and its interaction with ROI only affected a single 50-ms time window from 150 to $200 \mathrm{~ms}$ post fixation onset. During the N400 time window, there was no further effect except for the final $50 \mathrm{~ms}$. However, this influence is likely to stem from foveal processing of the target, which is often underway at this point. Thus, parafoveal FRPs did not show any significant modulations due to either frequency or predictability.

\section{Eye Movement Measures}

Analyses for the first fixation and gaze duration on the target word revealed two sizable main effects of word frequency and predictability. Low-frequency words led to longer fixation durations than highfrequency words (first fixation: $244 \mathrm{~ms}$ vs. $231 \mathrm{~ms}$; gaze duration: 277 ms vs. $248 \mathrm{~ms}$ ), and the same was observed for low-predictability targets versus high-predictability targets (first fixation: $247 \mathrm{~ms}$ vs. 228 ms; gaze duration: 279 ms vs. 246 ms; cf. Figure 4 and Table 5). The word frequency effect increased from first fixation to gaze duration (from a 13- to 29-ms difference between high- and low-frequency words; cf. the left panel of Figure 4), as did the predictability effect (from 19 to $33 \mathrm{~ms}$; cf. the middle panel of Figure 4). The interaction was not significant for either measure. The duration of the prior fixation revealed no reliable main effects, but a significant interaction between the two factors (cf. the right panel of Figure 4 and Table 5). When this interaction was resolved, it showed a predictability effect 
Table 3

Results of the Statistical Analysis for First Fixation-Related Potentials in 50-ms Time Windows From 150 to 700 ms Post Fixation Onset

\begin{tabular}{|c|c|c|c|c|c|c|c|c|c|c|c|}
\hline & \multicolumn{11}{|c|}{ Lateral electrode sites } \\
\hline & $150-200$ & $200-250$ & $250-300$ & $300-350$ & $350-400$ & $400-450$ & $450-500$ & $500-550$ & $550-600$ & $600-650$ & $650-700$ \\
\hline $\mathrm{F}$ & 1.23 & 1.68 & $<1$ & $<1$ & $<1$ & $<1$ & 1.89 & $4.21^{*}$ & 1.09 & $<1$ & 1.40 \\
\hline $\mathrm{R} \times \mathrm{F}$ & 1.84 & $<1$ & $\begin{array}{l}\mathbf{4 . 8 7}^{*} \\
\text { R1: }<1 \\
\text { R2: } 1.07 \\
\text { R3: } 2.64 \\
\text { R4: }<1\end{array}$ & $<1$ & $<1$ & $<1$ & $<1$ & 2.06 & 2.29 & 1.37 & 1.48 \\
\hline P & $14.26^{* * * *}$ & $9.52^{* * *}$ & $10.02^{* * *}$ & $23.71^{* * * *}$ & $20.58^{* * * *}$ & $30.34^{* * * *}$ & $9.57^{* *}$ & $12.22^{* *}$ & $6.66^{*}$ & $9.25^{* *}$ & $<1$ \\
\hline $\mathrm{R} \times \mathrm{P}$ & 1.49 & 1.33 & $<1$ & 1.06 & 1.95 & $\begin{array}{l}\mathbf{3 . 5 4}^{*} \\
\text { R1: } \mathbf{2 8 . 8 3}^{* * *} \\
\text { R2: } \mathbf{2 7 . 5 9}^{* * * *} \\
\text { R3: } \mathbf{2 2 . 4 4}^{* * * *} \\
\text { R4: } \mathbf{2 8 . 0 4}^{* * * * *}\end{array}$ & $<1$ & 2.05 & $<1$ & \begin{tabular}{l}
\multicolumn{1}{c}{$\mathbf{3 . 8 2}^{*}$} \\
R1: 3.87 \\
R2: $\mathbf{1 1 . 5 9}^{* *}$ \\
R3: 1.97 \\
R4: 11.06**
\end{tabular} & $\begin{array}{l}\quad \mathbf{6 . 5 8}^{\text {*** }} \\
\text { R1: }<1 \\
\text { R2: } \mathbf{5 . 3 5}^{*} \\
\text { R3: }<1 \\
\text { R4: }<1\end{array}$ \\
\hline $\mathrm{F} \times \mathrm{P}$ & $<1$ & 2.78 & 2.67 & $\begin{array}{l}\mathbf{4 . 9 3}^{*} \\
\text { LF: } \mathbf{2 8 . 0 5}^{* * * *} \\
\text { HF: } \mathbf{4 . 5 3}^{*}\end{array}$ & $<1$ & $<1$ & $<1$ & $<1$ & 2.49 & 1.49 & 1.41 \\
\hline \multirow[t]{2}{*}{$\begin{array}{l}\mathrm{R} \times \mathrm{F} \\
\times \mathrm{P}\end{array}$} & $<1$ & 1.75 & 1.26 & $<1$ & $<1$ & 1.56 & $\begin{array}{l}\begin{array}{l}\text { 4.98 }^{*} \\
\text { R1: }\end{array} \\
\text { R2: } 1.92 \\
\text { R3: }<1 \\
\text { R4: }<1\end{array}$ & $<1$ & $<1$ & 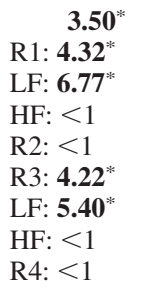 & 2.00 \\
\hline & \multicolumn{11}{|c|}{ Midline electrode sites } \\
\hline F & 1.04 & $<1$ & $<1$ & $<1$ & $<1$ & $<1$ & 2.74 & 1.68 & $<1$ & $<1$ & 1.41 \\
\hline $\mathrm{R} \times \mathrm{F}$ & $<1$ & $<1$ & 3.03 & $<1$ & 3.38 & $<1$ & $<1$ & $<1$ & $<1$ & $\begin{array}{r}\mathbf{5 . 9 8}^{*} \\
C P z:<1 \\
P z:<1\end{array}$ & 2.56 \\
\hline P & $12.50^{* *}$ & 7.07* & $9.18^{* * *}$ & $26.54^{* * * *}$ & $28.33^{* * * *}$ & $35.15^{* * * *}$ & $12.45^{* *}$ & $17.14^{* * * *}$ & $7.10^{*}$ & $9.65^{*}$ & 1.81 \\
\hline $\mathrm{R} \times \mathrm{P}$ & $<1$ & $<1$ & 1.09 & 1.20 & $<1$ & 2.40 & $<1$ & 1.80 & $<1$ & $<1$ & $\begin{array}{c}\mathbf{7 . 7 6}^{\text {*** }} \\
C P z: 3.56 \\
P z:<1\end{array}$ \\
\hline $\mathrm{F} \times \mathrm{P}$ & $<1$ & 2.75 & 1.86 & 3.46 & $<1$ & $<1$ & 1.30 & 1.78 & 3.55 & $\begin{array}{l}\mathbf{5 . 8 5}^{*} \\
\text { LF: } \mathbf{1 3 . 2 9}^{* * * *} \\
\text { HF: }<1\end{array}$ & 2.52 \\
\hline $\begin{array}{l}\mathrm{R} \times \mathrm{F} \\
\times \mathrm{P}\end{array}$ & $<1$ & 3.93 & $<1$ & $<1$ & $<1$ & 1.19 & $\begin{array}{c}\mathbf{6 . 6 8}^{*} \\
C P z: 1.74 \\
P z:<1\end{array}$ & $<1$ & $<1$ & $<1$ & $<1$ \\
\hline
\end{tabular}

Note. The table shows $F$ values. For all simple effects of frequency and predictability and the interaction between the two, $d f=(1,37)$. For all interactions involving region of interest $(\mathrm{ROI}), d f=(3,111) . \mathrm{F}=$ frequency; $\mathrm{R} \times \mathrm{F}=\mathrm{ROI} \times$ Frequency; $\mathrm{P}=$ predictability; $\mathrm{R} \times \mathrm{P}=\mathrm{ROI} \times \mathrm{Predictability} ; \mathrm{F} \times$ $\mathrm{P}=$ Frequency $\times$ Predictability; $\mathrm{R} \times \mathrm{F} \times \mathrm{P}=\mathrm{ROI} \times$ Frequency $\times$ Predictability; $\mathrm{R} 1=$ left centro-parietal; $\mathrm{R} 2=$ right centro-parietal; $\mathrm{R} 3=$ left parietal; $\mathrm{R} 4$ = right parietal; $\mathrm{LF}=$ low-frequency word; $\mathrm{HF}=$ high-frequency word. Significant effects are in bold. Main effects of ROI are not reported.

${ }^{*} p<.05 .{ }^{* * *} p<.01 .{ }^{* * * *} p<.001$

for high-frequency words (223 for predictable vs. 235 for unpredictable targets; $\left.F_{1}(1,37)=15.91, p<.001 ; F_{2}(1,39)=4.62, p<.05\right)$, whereas the 2-ms difference for low-frequency words was not significant $(F<1)$. Note, however, that it is difficult to treat this interaction as meaningful with respect to the current manipulations. First and foremost, the words preceding the target were not equated across the four conditions. The interaction may thus have its origin in different launch sites and hence parafoveal previews of the critical word across trials, which cannot be interpreted in a meaningful manner. This is moreover reflected in the direction of the interaction that is not predicted by any theoretical account of word recognition.

The two saccadic measures showed a highly comparable pattern as concerns the lack of a statistical interaction (cf. Table 6). Regression rates showed only a main effect of predictability, reflecting fewer regressions from predictable targets (.075 vs. .12). Frequency and the interaction of both variables did not reliably influence the probability of leaving the target with a regressive saccade. For the skipping rate, both main effects were fully reliable, whereas the interaction was not significant. Targets were skipped more often when they were either frequent (.23 vs. .18) or expected (.22 vs. .19).

\section{Discussion}

The present study aimed to assess whether dissociations between word frequency and predictability effects in eye movements and EEGs are obtained when both types of data are recorded from 


\section{A - Predictability Effect}
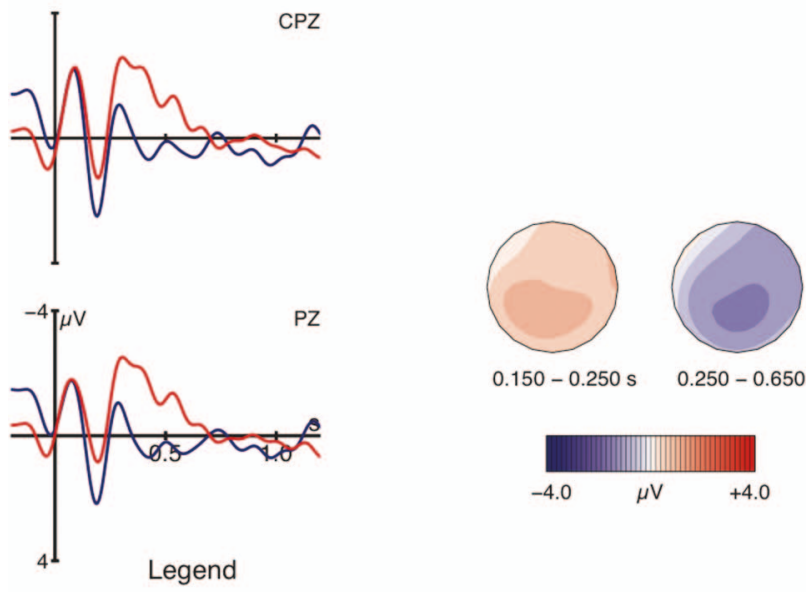

$0.150-0.250 \mathrm{~s}$

$0.250-0.650 \mathrm{~s}$

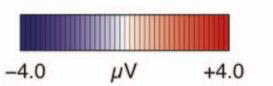

\section{B - Frequency Effect}

$\mathrm{CPZ}$
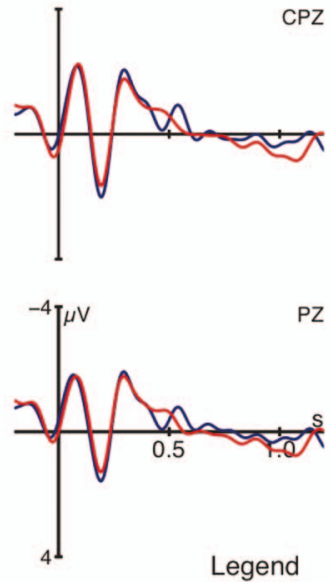

PZ
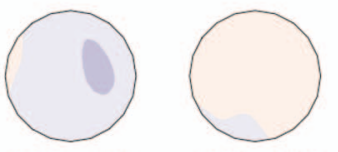

$0.150-0.250 \mathrm{~s}$

$0.250-0.650 s$

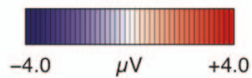

Legend

- High Predictability

— High Frequency

Low Predictability

Low Frequency

Figure 2. Grand average fixation-related potentials (FRPs) time-locked to the onset of the first fixation on the target word (vertical bar). FRPs are collapsed across the factor frequency in order to show the predictability effect (Panel A) or across the factor predictability in order to show the frequency effect (Panel B). Topographical maps show the scalp distributions for the differences between conditions in the P200 and N400 time windows, respectively. See the online article for the color version of this figure.

the very same trials in natural reading. The study clearly replicated the previously reported additive effects of the two variables in the eye movement record: low-frequency words increased fixation durations compared to high-frequency words; the same was true for unpredictable versus predictable words. The regression rate and skipping rate also failed to provide evidence for a statistical interaction. Predictability influenced both measures, with fewer regressions from, and more skipping of, expected targets, while frequency only modulated skipping rates such that low-frequency words were skipped less often. The predictability of a word also

\section{Prior Fixation-related Potentials}
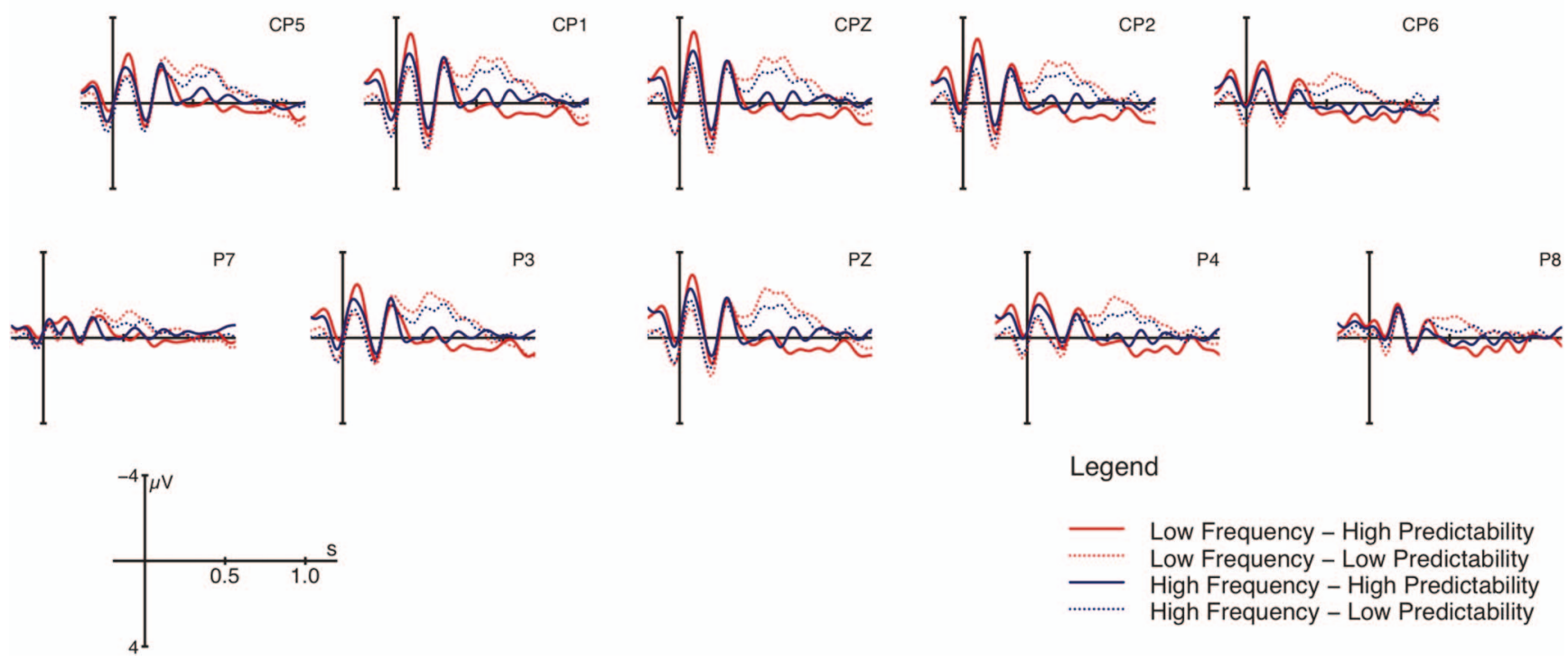

Legend

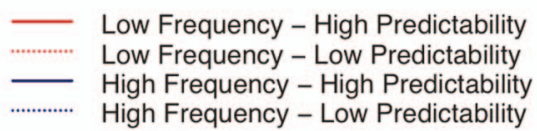

Figure 3. Grand average fixation-related potentials (FRPs) time-locked to the onset of the fixation prior to the target word (vertical bar). Negativity is plotted upward. FRPs were smoothed with an 8-Hz low-pass filter for visual presentation only. See the online article for the color version of this figure. 
Table 4

Results of the Statistical Analysis for Prior Fixation-Related Potentials in 50-ms Time Windows From 150 to 400 ms Post Fixation Onset

\begin{tabular}{|c|c|c|c|c|c|}
\hline & \multicolumn{5}{|c|}{ Lateral electrode sites } \\
\hline & $150-200$ & $200-250$ & $250-300$ & $300-350$ & $350-400$ \\
\hline $\mathrm{F}$ & $<1$ & 1.74 & $<1$ & 3.96 & $4.17^{*}$ \\
\hline $\mathrm{R} \times \mathrm{F}$ & $<1$ & 1.34 & 2.01 & $<1$ & 1.55 \\
\hline $\mathrm{P}$ & $6.66^{*}$ & 1.39 & $<1$ & $<1$ & $6.88^{*}$ \\
\hline \multirow[t]{5}{*}{$\mathrm{R} \times \mathrm{P}$} & $6.81^{*}$ & 2.72 & 1.23 & 1.47 & $\mathbf{7 . 3 3}^{*}$ \\
\hline & $\mathrm{R} 1: \mathbf{6 . 5 7 *}$ & & & & $\mathrm{R} 1: \mathbf{1 5 . 1 6}^{* * *}$ \\
\hline & R2: $10.86^{* *}$ & & & & $\mathrm{R} 2: 2.97$ \\
\hline & R3: 1.24 & & & & R3: $10.68^{* *}$ \\
\hline & $\mathrm{R} 4: \mathbf{5 . 8 3}{ }^{*}$ & & & & R4: 1.66 \\
\hline $\mathrm{F} \times \mathrm{P}$ & $<1$ & $<1$ & $<1$ & $<1$ & $<1$ \\
\hline \multirow[t]{2}{*}{$\mathrm{R} \times \mathrm{F} \times \mathrm{P}$} & 2.12 & $<1$ & $<1$ & 1.85 & $<1$ \\
\hline & \multicolumn{5}{|c|}{ Midline electrode sites } \\
\hline $\mathrm{F}$ & $<1$ & 2.41 & $<1$ & 2.28 & 1.86 \\
\hline $\mathrm{R} \times \mathrm{F}$ & 1.52 & $<1$ & 1.83 & $<1$ & $<1$ \\
\hline $\mathrm{P}$ & $7.97^{* *}$ & 1.82 & $<1$ & $<1$ & 4.39* \\
\hline $\mathrm{R} \times \mathrm{P}$ & $\begin{array}{c}\mathbf{8 . 9 1}^{* *} \\
C P z: 9.73^{* *} \\
P z: 6.17^{*}\end{array}$ & $<1$ & $<1$ & $<1$ & 3.11 \\
\hline $\mathrm{F} \times \mathrm{P}$ & $<1$ & $<1$ & $<1$ & $<1$ & $<1$ \\
\hline $\mathrm{R} \times \mathrm{F} \times \mathrm{P}$ & $<1$ & $<1$ & $<1$ & $<1$ & 1.44 \\
\hline
\end{tabular}

Note. The table shows $F$ values. For all simple effects of frequency and predictability and the interaction between the two, $d f=(1,37)$. For all interactions involving region of interest $(\mathrm{ROI}), d f=(3,111) . \mathrm{F}=$ frequency; $\mathrm{R} \times \mathrm{F}=\mathrm{ROI} \times$ Frequency; $\mathrm{P}=$ predictability; $\mathrm{R} \times \mathrm{P}=\mathrm{ROI} \times$ Predictability; $F \times$ P: Frequency $\times$ Predictability; $\mathrm{R} \times \mathrm{F} \times \mathrm{P}=\mathrm{ROI} \times$ Frequency $\times$ Predictability; R1 = left centro-parietal; R2 = right centroparietal; R3 = left parietal; R4 = right parietal; LF = low-frequency word; $\mathrm{HF}=$ high-frequency word. Significant effects are in bold. Main effects of ROI are not reported.

${ }^{*} p<.05 .{ }^{* *} p<.01 .{ }^{* * * *} p<.001$.

strongly affected FRPs, with predictable words leading to more positive waveforms overall as reflected in smaller N400 amplitude and increased P200 amplitude. This predictability effect was registered when FRPs were time-locked to the onset of the first fixation on a word. There were no reliable parafoveal N400 or P200 effects of predictability in our FRP data, as is expected if predictability is not perfect (cf. Kretzschmar et al., 2009). Critically, the electrophysiological data replicated the absence of the N400 frequency effect for target words that are preceded by sentence context. In sum, we replicate previous results from separate RSVP and eye movement studies with predictability influencing both the N400 amplitude and eye movement control, but with word frequency only influencing the latter. These results add further support for the claim that contextual factors can cancel out the influence of frequency-based bottom-up information on the N400 (cf. Van Petten \& Kutas, 1990, 1991). This pattern has implications for the linking of eye movements with endogenous ERP components and for the interpretation of the N400 itself.

With respect to the first implication, one hypothesis outlined in the Introduction suggested that the faster and partly parallel information uptake in natural reading might be able to reveal frequency effects on the N400, in contrast to the slower and strictly serial information uptake in RSVP settings. From this perspective, differential frequency effects on eye movements and the N400 may be primarily due to differences in presentation format between the two experimental paradigms. However, our findings suggest that the previously observed pattern of $\mathrm{N} 400$ effects in sentence reading is not due to the somewhat artificial reading situation and slower information uptake with RSVP. While we found fairly typical N400 predictability effects, with the expected onset latency (see Figure 1), we did not find N400 frequency effects. Together with the findings from separate experiments manipulating RSVP rate, these findings make clear that the features of RSVP itself cannot account for different word frequency effects in eye movement and electrophysiological records when words are embedded in meaningful sentences.

If word frequency affects eye movements in general, but not the N400 in response to words preceded by substantial sentence context, can this be considered evidence for the second hypothesis that there is no one-to-one equivalence between N400 amplitude and fixation durations in sentence processing? In assessing this hypothesis, one needs to consider further findings from combined EEGeyetracking experiments as well as possible functional interpretations of the N400 component. It is beyond the scope of the present paper to discuss in detail all relevant findings from combined EEG-eyetracking in reading, but it is notable that the literature comparing FRP amplitudes and fixation duration effects suggests that, in many instances, there is only weak dependence between the two measures. Parafoveal processing in particular shows an inconsistent pattern in that effects in either measure may emerge in the absence of effects in the other. Specifically, while some studies found parafoveal effects in the FRP record without concomitant effects on the corresponding fixation duration (e.g., Baccino \& Manunta, 2005; Kretzschmar et al., 2009; Simola et al., 2009), others have reported the reversed pattern (e.g., Dimigen, Kliegl, \& Sommer, 2012). Even though correlations between FRPs and fixation durations have been reported for foveal processes (Dimigen et al., 2011; Kretzschmar et al., 2009), the present study adds to the body of evidence that FRPs do not necessarily correlate with the duration of the triggering fixation and that it is not clear which eye movement measures do correlate with FRP effects. Overall, the literature argues in favor of a partial decoupling of information types that may be reflected in an ERP-FRP component and that influence oculomotor behavior when the duration of just one fixation is considered. This may complement as-yet other unexplained findings from the ERP literature showing dissociations between behavioral response latencies and the N400 amplitude (e.g., Bornkessel, McElree, Schlesewsky, \& Friederici, 2004; Brown \& Hagoort, 1993; Holcomb, 1993; Sassenhagen, Schlesewsky, \& Bornkessel-Schlesewsky, 2014).

However, the record of eye movements during reading offers a multitude of fixation-based measures, including accumulative ones such as gaze duration or total time spent on a target word, as well as saccadic measures such as the probability of making a regressive saccade in order to reread previous parts of a sentence. Some have argued that the timing of the N400 in FRPs is too late to correspond to the timing of the eye movement decisions that determine the duration of the fixation in question (i.e., the fixation to which the FRP is time-locked) and should thus be expected to correlate with the duration of the following fixation (e.g., Dambacher \& Kliegl, 2007; Sereno \& Rayner, 2003). This view predicts that effects on N400 amplitude may also correspond to effects on refixation probability, and hence accumulative fixation 
Table 5

Summary of the Statistical Analysis for the Target Word With First Fixation Duration, Gaze Duration, and Prior Fixation Duration

\begin{tabular}{lcc}
\hline & $F_{1}(1,37)$ & $F_{2}(1,78)$ \\
\hline First fixation duration & & \\
Frequency & $30.14^{* * * *}$ & $16.86^{* * * *}$ \\
Predictability & $108.04^{* * * *}$ & $56.78^{* * *}$ \\
Frequency $\times$ Predictability & 4.02 & 1.48 \\
Gaze duration & & \\
Frequency & $91.15^{* * * *}$ & $33.53^{* * *}$ \\
Predictability & $66.49^{* * * *}$ & $65.56^{* * * *}$ \\
Frequency $\times$ Predictability & 0.68 & 0.20 \\
Prior fixation duration & & \\
Frequency & 0.41 & $<1$ \\
Predictability & $5.20^{*}$ & 1.61 \\
Frequency $\times$ Predictability & $13.28^{* * *}$ & $4.13^{* *}$ \\
\hline
\end{tabular}

Note. The table shows $F$ values.

${ }^{*} p<.05 . \quad{ }^{* * *} p<.01 .^{* * *} p<.001$.

measures, on the target word. Clearly, more research is necessary to uncover the relationship between the N400 and multiple fixations that may be triggered by the very same cognitive function. While this view could account for N400 effects that co-occur with effects in the eye movement record other than effects on first fixation duration, it is of course not as well suited to explain the pattern that appeared in the present experiment-that is, an eye movement effect in the absence of an N400 modulation. In addition, this view does not offer an explanation for why the predictability manipulation does influence the N400 in FRPs, but the frequency manipulation does not.

We now turn to implications of the current data for theories of the N400 and, in particular, the types of information and cognitive processes that may underlie N400 generation. Since the discovery of the N400 in the early 1980s, there have been extensive theoretical debates regarding its functional significance (see Kutas \& Federmeier, 2011, and Lau, Phillips, \& Poeppel, 2008, for more recent overviews). In the sentence-processing literature, including the literature on word recognition in context, it is possible to distinguish three positions. In the following, we briefly discuss to what extent these positions may account for the present results. Note that all of these accounts assign predictability a pivotal role in determining
N400 amplitude, so the following descriptions will focus on the role of word frequency as one type of bottom-up information.

According to the first account, the lexical view, the N400 reflects lexical access itself, and any effects of context on the N400 can be explained by means of preactivation of lexical features. In its strongest version, this account predicts that, similar to eye movements, word frequency should reliably influence N400 amplitude, on the common assumption (e.g., Reichle et al., 2003) that the effect of word frequency on eye movements is an effect on lexical processing (cf. Lau et al., 2008). Clearly, this prediction is not uniformly borne out across experiments.

The second approach assumes that the N400 amplitude mainly reflects the difficulty of integration of the current word with previously processed information at a postlexical stage, because even N400 onset occurs too late to reflect lexical access (e.g., Brown \& Hagoort, 1993; Sereno \& Rayner, 2003). Frequency as a lexical variable should not affect postlexical stages in processing, and hence the pattern found for the lack of the N400 frequency effect in sentence reading is expected. Yet, it remains unexplained why word frequency modulates the N400 in some single-word recognition experiments or at the beginning of sentences.

Thus, it appears that categorizing the N400 as either lexical or postlexical does not account for the full complexities of the data reported in the literature (see also Kutas \& Federmeier, 2011). More recently, a third class of N400 theories has therefore abstracted away from this dimension and has instead attempted to explain the component's behavior by referring to the potential interaction between bottom-up and top-down information. This interactive account subsumes at least two different variants that differ in the way in which bottom-up information may be used. On both accounts, the N400 should always be reduced when the input matches a prediction, but the accounts differ in how they explain the impact of mismatching bottom-up information.

On the first of these variants, proposed by Kutas and Federmeier (2011), the N400 is assumed to index activation in a semantic network in long-term memory that follows any modality-specific processing; the amplitude of the N400 is determined by the degree of change in this level of activation brought about by the current stimulus. Activation levels within this semantic network are assumed to be induced by stimulus properties and thus dependent upon a feedforward sweep of bottom-up information. However, the consequences of bottom-up induced activity also vary as a
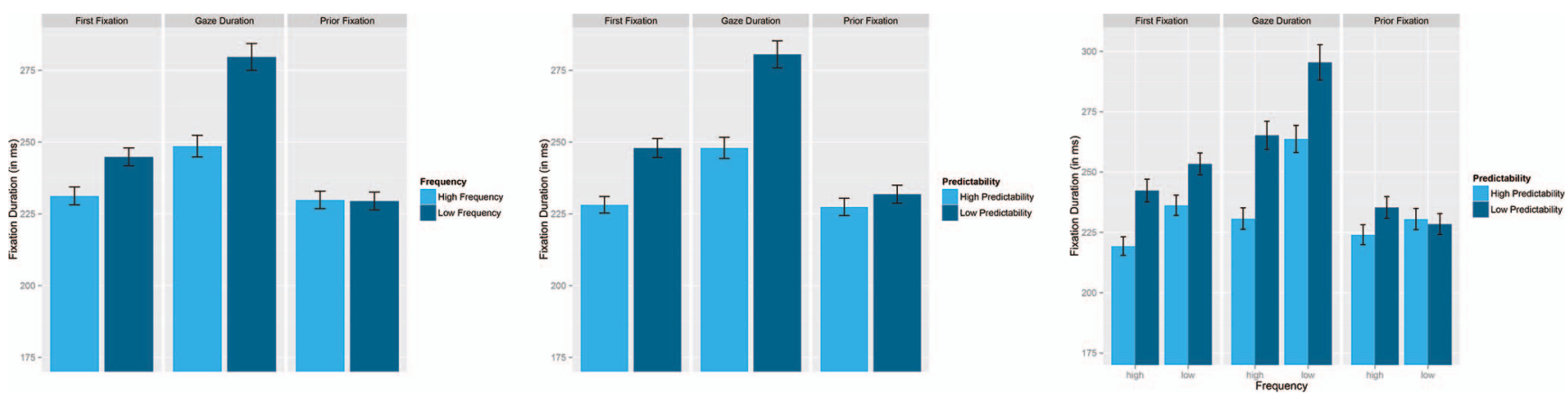

Figure 4. Mean fixation durations for the target word. The left panel shows the frequency effect, the middle panel shows the predictability effect, and the right panel shows the interaction between frequency and predictability. See the online article for the color version of this figure. 
Table 6

Top Panel: Participant Means for First-Pass Regressions and Skipping Rate per Condition for the Target Word. Standard Deviations Are Given in Parentheses. Bottom Panel: Results for the Analyses of Variance (ANOVAs) Carried Out for Empirical Logit Transformations

\begin{tabular}{lcr}
\hline \multicolumn{1}{c}{ Condition } & First-pass regressions & Skipping rate \\
\hline & & Means \\
Low frequency-high predictability & $.09(.06)$ & $.18(.12)$ \\
Low frequency-low predictability & $.12(.08)$ & $.18(.13)$ \\
High frequency-high predictability & $.06(.05)$ & $.26(.12)$ \\
High frequency-low predictability & $.12(.08)$ & $.20(.10)$ \\
\hline
\end{tabular}

\begin{tabular}{|c|c|c|c|c|}
\hline & \multicolumn{4}{|c|}{ ANOVA } \\
\hline & $F_{1}(1,37)$ & $F_{2}(1,78)$ & $F_{1}(1,37)$ & $F_{2}(1,78)$ \\
\hline Frequency & 2.46 & 3.55 & $\overline{13.07^{* * * * *}}$ & $5.17^{*}$ \\
\hline Predictability & $12.38^{* *}$ & $16.20^{* * * *}$ & $6.65^{*}$ & $6.30^{*}$ \\
\hline Frequency $\times$ Predictability & 2.87 & 2.44 & 2.65 & 3.68 \\
\hline
\end{tabular}

Note. The table shows $F$ values.

${ }^{*} p<.05 .{ }^{* * *} p<.01 .{ }^{* * * *} p<.001$.

function of memory internal computations such as the generation of predictions about upcoming stimuli. The spread of bottom-up information can thus have different consequences depending on how it interacts with a specific activation level of the semantic network. Activation of specific information features within the semantic network is based on the spread of activation, whose strength and direction depends on both the incoming stimulus and on system-internal predictions derived from prior processing or activation states.

The way in which such bottom-up stimulus information and top-down predictions generated in semantic memory may interact has been elaborated in another related account called the bidirectional coding account (Lotze, Tune, Schlesewsky, \& BornkesselSchlesewsky, 2011; Tune et al., 2014). According to this approach, the semantic network actively generates predictions about upcoming stimuli, which specifically include their assumed activation level (called referent accessibility). Any perceived bottom-up information is then evaluated in terms of how it meets these predictions-that is, whether it signals the predicted activation level. Critically, and contrary to the first interactive account, the N400 amplitude modulation does not merely reflect the mismatch between bottom-up information and predictions but rather indexes the extent to which bottom-up information diverges from the activation level predicted in a top-down manner. Thus, even if a new stimulus mismatches the system's prediction on one dimension, it can still convey information on another dimension that could potentially reduce N400 amplitude. For example, Lotze et al. (2011) investigated to what extent the case of sentence-final words interferes with implausibility detection. They found that the N400 amplitude increase for implausible words was smaller if these words were written entirely in capital letters. Here, the orthographic word form signaled a mismatch between the perceived stimulus and the prediction that another plausible word should have terminated the sentence. Lotze et al. (2011) argued that even though a word's case by itself is not relevant for evaluating whether a word is a plausible sentence continuation, the extralinguistic meaning of uppercase lettering (e.g., irony, emotional emphasis) may be interpreted as a possible justification for an other- wise semantically deviant meaning. Thus, one and the same stimulus can offer different types of bottom-up information, and these may be weighted differently during processing (cf. Tune et al., 2014, for the cross-linguistic applicability of this proposal). While some stimulus features induce a mismatch, others can additionally be used interpretatively to reduce the effort of integrating the mismatching information.

As outlined above, both interactive approaches assume a rather constant influence of top-down predictions on the N400 amplitude but assign bottom-up information a more flexible status. If the latter assumption is correct, we may expect to find that bottom-up information in general should show weak, or at least less systematic, impact on the N400 amplitude across studies. Within the field of written word recognition, this seems to be the case, as some modality-specific bottom-up information that does affect eye movements or other behavioral measures has been shown to only affect ERP components before the N400. Such bottom-up information first and foremost includes variables affecting the legibility of text such as font, interletter spacing, or contrast, all of which have repeatedly been shown to modulate fixation durations (e.g., Kretzschmar et al., 2013; Paterson \& Jordan, 2010; Rayner, Reichle, Stroud, Williams, \& Pollatsek, 2006; Reingold \& Rayner, 2006; White \& Staub, 2012) and ERP components with a peak latency of around $150 \mathrm{~ms}$ after word onset (Chauncey, Holcomb, \& Grainger, 2008; Pickering \& Schweinberger, 2003; VegaraMartínez, Gómez, Jiménez, \& Perea, in press). Yet, variables relating to the visual appearance of script usually do not seem to modulate N400 amplitude. Masked priming experiments, for instance, have consistently revealed that features like font or case affect early sensory components but have no impact after about $200 \mathrm{~ms}$ after the onset of the target word. For example, Chauncey et al. (2008) reported that with a semantic category detection task, font affected early visual analysis reflected in the N/P150 but not the N400. In another study, Vergara-Martínez and colleagues (in press) investigated how case identity versus difference within prime-target pairs affected ERPs in a lexical decision task and found a similar time course. The N/P150 was sensitive to case mismatches for both words and pseudowords. Yet, both the N250 
and N400 components did not differentially respond to case changes between prime and target for words. Finally, Holcomb (1993) investigated semantic priming effects in a lexical decision task with visually intact target words and degraded stimuli. He found that degrading letter shapes by removing pixels or by overlaying a mask on the target word had a negative impact on N400 latency, reaction times, and error rates but, again, no effect on N400 amplitude.

What these types of bottom-up information have in common is that they are not particularly relevant for meeting top-down expectations induced by experimental tasks such as lexical decision or semantic category detection. These tasks should preactivate and predict semantic features and abstract orthographic codes, but not visual features relating to the appearance of script. This assumption lines up well with a recent study that has convincingly argued for effects of task demands on the N400 frequency effect in single-word reading. In that study (Fischer-Baum, Dickson, \& Federmeier, 2014; see also Laszlo \& Federmeier, 2011), participants either had to read individual items aloud in a word list or detect a proper name. Word frequency modulated N400 amplitude in the reading aloud task, but not in the proper-name detection task. The authors reasoned that different tasks set up different contextual constraints on which predictions are based. As the reading-aloud task presumably provides the least constraining context, frequency can influence semantic access, whereas the propername detection task activates a set of semantic features more or less independent of word frequency.

Overall, this seems to suggest that bottom-up information impacts N400 amplitude whenever context-be it linguistic context or experimentally induced task context-allows participants to generate predictions against which bottom-up stimulus information can be matched and when stimulus features are potentially relevant to satisfying a prediction or reducing mismatch costs so that they interact with semantic memory. From this perspective, the lack of an N400 frequency effect in the current experiment and earlier studies is not surprising, assuming that word frequency as bottom-up information is not substantially relevant to meeting top-down predictions about upcoming words in a sentence. Nonetheless, when contextual information is missing, as is the case in some single-word tasks or for sentence-initial words, word frequency may be a strong predictor of N400 amplitude, given that in such tasks, word frequency itself may be a strong source of lexical expectations (e.g., Norris, 2006).

While this is compatible with the interactive accounts of the $\mathrm{N} 400$, the present data and proposed explanations also suggest that frequency effects in the eye movement record and the N400 reflect partly differing cognitive functions. Whereas frequency directly influences lexical processing and therefore eye fixation durations, as well as ERP components before the N400 (cf. Hauk \& Pulvermuller, 2004; Reichle, Tokowicz, Liu, \& Perfetti, 2011), the N400 reflects aspects of the interaction between top-down predictions (word predictability) and bottom-up information (word frequency).

\section{Conclusion}

We investigated the discrepancy between eye movement and ERP data with regard to lexical frequency and predictability effects in reading by means of a concurrent EEG-eyetracking experiment. Our data suggest that previous contradictory findings from eye movement and ERP studies with regard to word frequency effects in sentence processing do not result from mere methodical differences relating to presentation format (RSVP vs. natural reading). In sentence contexts, word frequency does not modulate N400 amplitude in either ERP or FRP measures but reliably influences fixation durations. It appears that there is no one-to-one equivalence between the N400 amplitude and fixation durations in sentence processing. We suggest that this may be because the N400 is sensitive not to the difficulty of lexical processing itself but to the interaction of top-down predictions and bottom-up information, especially when the latter provides cues relevant for matching a prediction. Lexical frequency in context does not appear to provide bottom-up information relevant to meeting top-down predictions in natural sentence or story comprehension.

\section{References}

Altarriba, J., Kroll, J. F., Sholl, A., \& Rayner, K. (1996). The influence of lexical and conceptual constraints on reading mixed-language sentences: Evidence from eye fixations and naming times. Memory \& Cognition, 24, 477-492. http://dx.doi.org/10.3758/BF03200936

Ashby, J., Rayner, K., \& Clifton, C., Jr. (2005). Eye movements of highly skilled and average readers: Differential effects of frequency and predictability. The Quarterly Journal of Experimental Psychology, 58, 1065-1086. http://dx.doi.org/10.1080/02724980443000476

Baccino, T., \& Manunta, Y. (2005). Eye-fixation-related potentials: Insight into parafoveal processing. Journal of Psychophysiology, 19, 204-215. http://dx.doi.org/10.1027/0269-8803.19.3.204

Balota, D. A., Yap, M. J., Hutchison, K. A., Cortese, M. J., Kessler, B., Loftis, B., .. . Treiman, R. (2007). The English lexicon project. Behavior Research Methods, 39, 445-459. http://dx.doi.org/10.3758/BF03193014

Barber, H., Vergara, M., \& Carreiras, M. (2004). Syllable-frequency effects in visual word recognition: Evidence from ERPs. Neuroreport, 15, 545-548. http://dx.doi.org/10.1097/00001756-200403010-00032

Barr, D. J. (2008). Analyzing "visual world" eyetracking data using multilevel logistic regression. Journal of Memory and Language, 59, 457474. http://dx.doi.org/10.1016/j.jml.2007.09.002

Bélanger, N. N., \& Rayner, K. (2013). Frequency and predictability effects in eye fixations for skilled and less-skilled deaf readers. Visual Cognition, 21, 477-497. http://dx.doi.org/10.1080/13506285.2013.804016

Bornkessel, I., McElree, B., Schlesewsky, M., \& Friederici, A. D. (2004). Multi-dimensional contributions to garden path strength: Dissociating phrase structure from case marking. Journal of Memory and Language, 51, 495-522. http://dx.doi.org/10.1016/j.jml.2004.06.011

Brown, C., \& Hagoort, P. (1993). The processing nature of the N400: Evidence from masked priming. Journal of Cognitive Neuroscience, 5 , 34-44. http://dx.doi.org/10.1162/jocn.1993.5.1.34

Brown, C. M., Hagoort, P., \& ter Keurs, M. (1999). Electrophysiological signatures of visual lexical processing: Open- and closed-class words. Journal of Cognitive Neuroscience, 11, 261-281. http://dx.doi.org/ $10.1162 / 089892999563382$

Brysbaert, M., \& New, B. (2009). Moving beyond Kučera and Francis: A critical evaluation of current word frequency norms and the introduction of a new and improved word frequency measure for American English. Behavior Research Methods, 41, 977-990. http://dx.doi.org/10.3758/ BRM.41.4.977

Chauncey, K., Holcomb, P. J., \& Grainger, J. (2008). Effects of stimulus font and size on masked repetition priming: An event-related potentials (ERP) investigation. Language and Cognitive Processes, 23, 183-200. http://dx.doi.org/10.1080/01690960701579839

Condray, R., Siegle, G. J., Keshavan, M. S., \& Steinhauer, S. R. (2010). Effects of word frequency on semantic memory in schizophrenia: Elec- 
trophysiological evidence for a deficit in linguistic access. International Journal of Psychophysiology, 75, 141-156. http://dx.doi.org/10.1016/j .ijpsycho.2009.10.010

Connolly, J. F., \& Phillips, N. A. (1994). Event-related potential components reflect phonological and semantic processing of the terminal word of spoken sentences. Journal of Cognitive Neuroscience, 6, 256-266. http://dx.doi.org/10.1162/jocn.1994.6.3.256

Dambacher, M., Dimigen, O., Braun, M., Wille, K., Jacobs, A. M., \& Kliegl, R. (2012). Stimulus onset asynchrony and the timeline of word recognition: Event-related potentials during sentence reading. Neuropsychologia, 50, 1852-1870. http://dx.doi.org/10.1016/j.neuropsychologia .2012 .04 .011

Dambacher, M., \& Kliegl, R. (2007). Synchronizing timelines: Relations between fixation durations and N400 amplitudes during sentence reading. Brain Research, 1155, 147-162.

Dambacher, M., Kliegl, R., Hofmann, M., \& Jacobs, A. M. (2006). Frequency and predictability effects on event-related potentials during reading. Brain Research, 1084, 89-103. http://dx.doi.org/10.1016/j .brainres.2006.02.010

DeLong, K. A., Urbach, T. P., \& Kutas, M. (2005). Probabilistic word pre-activation during language comprehension inferred from electrical brain activity. Nature Neuroscience, 8, 1117-1121. http://dx.doi.org/ 10.1038/nn1504

Dimigen, O., Kliegl, R., \& Sommer, W. (2012). Trans-saccadic parafoveal preview benefits in fluent reading: A study with fixation-related brain potentials. NeuroImage, 62, 381-393. http://dx.doi.org/10.1016/j .neuroimage.2012.04.006

Dimigen, O., Sommer, W., Hohlfeld, A., Jacobs, A. M., \& Kliegl, R. (2011). Coregistration of eye movements and EEG in natural reading: Analyses and review. Journal of Experimental Psychology: General, 140, 552-572. http://dx.doi.org/10.1037/a0023885

Drieghe, D., Rayner, K., \& Pollatsek, A. (2005). Eye movements and word skipping during reading revisited. Journal of Experimental Psychology: Human Perception and Performance, 31, 954-969. http://dx.doi.org/ 10.1037/0096-1523.31.5.954

Ehrlich, S. F., \& Rayner, K. (1981). Contextual effects on word perception and eye movements during reading. Journal of Verbal Learning \& Verbal Behavior, 20, 641-655. http://dx.doi.org/10.1016/S00225371(81)90220-6

Engbert, R., Nuthmann, A., Richter, E. M., \& Kliegl, R. (2005). SWIFT: A dynamical model of saccade generation during reading. Psychological Review, 112, 777-813.

Federmeier, K. D., \& Kutas, M. (1999). A rose by any other name: Long-term memory structure and sentence processing. Journal of Memory and Language, 41, 469-495. http://dx.doi.org/10.1006/jmla.1999 .2660

Fischer-Baum, S., Dickson, D. S., \& Federmeier, K. D. (2014). Frequency and regularity effects in reading are task dependent: Evidence from ERPs. Language, Cognition and Neuroscience, 29, 1342-1355. http:// dx.doi.org/10.1080/23273798.2014.927067

Frank, S. L., Otten, L. J., Galli, G., \& Vigliocco, G. (2015). The ERP response to the amount of information conveyed by words in sentences. Brain and Language, 140, 1-11. http://dx.doi.org/10.1016/j.bandl.2014 .10 .006

Gallistel, C. R. (2009). The importance of proving the null. Psychological Review, 116, 439-453. http://dx.doi.org/10.1037/a0015251

Gollan, T. H., Slattery, T. J., Goldenberg, D., Van Assche, E., Duyck, W., \& Rayner, K. (2011). Frequency drives lexical access in reading but not in speaking: The frequency-lag hypothesis. Journal of Experimental Psychology: General, 140, 186-209. http://dx.doi.org/10.1037/ a0022256

Grainger, J., Lopez, D., Eddy, M., Dufau, S., \& Holcomb, P. J. (2012). How word frequency modulates masked repetition priming: An ERP investigation. Psychophysiology, 49, 604-616. http://dx.doi.org/ 10.1111/j.1469-8986.2011.01337.x

Gunter, T. C., Friederici, A. D., \& Schriefers, H. (2000). Syntactic gender and semantic expectancy: ERPs reveal early autonomy and late interaction. Journal of Cognitive Neuroscience, 12, 556-568. http://dx.doi.org/ $10.1162 / 089892900562336$

Halgren, E., Dhond, R. P., Christensen, N., Van Petten, C., Marinkovic, K., Lewine, J. D., \& Dale, A. M. (2002). N400-like magnetoencephalography responses modulated by semantic context, word frequency, and lexical class in sentences. NeuroImage, 17, 1101-1116. http://dx.doi .org/10.1006/nimg.2002.1268

Hand, C. J., Miellet, S., O'Donnell, P. J., \& Sereno, S. C. (2010). The frequency-predictability interaction in reading: It depends where you're coming from. Journal of Experimental Psychology: Human Perception and Performance, 36, 1294-1313. http://dx.doi.org/10.1037/a0020363

Hauk, O., \& Pulvermüller, F. (2004). Effects of word length and frequency on the human event-related potential. Clinical Neurophysiology, 115, 1090-1103. http://dx.doi.org/10.1016/j.clinph.2003.12.020

Holcomb, P. J. (1993). Semantic priming and stimulus degradation: Implications for the role of the N400 in language processing. Psychophysiology, 30, 47-61. http://dx.doi.org/10.1111/j.1469-8986.1993 tb03204.x

Huynh, H., \& Feldt, L. S. (1970). Conditions under which the mean-square ratios in repeated measurement designs have exact F-distributions. Jour nal of the American Statistical Association, 65, 1582-1589. http://dx.doi .org/10.1080/01621459.1970.10481187

Inhoff, A. W., \& Rayner, K. (1986). Parafoveal word processing during eye fixations in reading: Effects of word frequency. Perception \& Psychophysics, 40, 431-439. http://dx.doi.org/10.3758/BF03208203

Kennedy, A., Pynte, J., Murray, W. S., \& Paul, S.-A. (2013). Frequency and predictability effects in the Dundee Corpus: An eye movement analysis. The Quarterly Journal of Experimental Psychology, 66, 601618. http://dx.doi.org/10.1080/17470218.2012.676054

Kliegl, R., Grabner, E., Rolfs, M., \& Engbert, R. (2004). Length, frequency, and predictability effects of words on eye movements in reading. European Journal of Cognitive Psychology, 16, 262-284. http://dx .doi.org/10.1080/09541440340000213

Kliegl, R., Nuthmann, A., \& Engbert, R. (2006). Tracking the mind during reading: The influence of past, present, and future words on fixation durations. Journal of Experimental Psychology: General, 135, 12-35. http://dx.doi.org/10.1037/0096-3445.135.1.12

Kretzschmar, F., Bornkessel-Schlesewsky, I., \& Schlesewsky, M. (2009). Parafoveal versus foveal N400s dissociate spreading activation from contextual fit. Neuroreport, 20, 1613-1618. http://dx.doi.org/10.1097/ WNR.0b013e328332c4f4

Kretzschmar, F., Pleimling, D., Hosemann, J., Füssel, S., BornkesselSchlesewsky, I., \& Schlesewsky, M. (2013). Subjective impressions do not mirror online reading effort: Concurrent EEG-eyetracking evidence from the reading of books and digital media. PLOS ONE, 8, e56178. http://dx.doi.org/10.1371/journal.pone.0056178

Kutas, M., \& Federmeier, K. D. (2011). Thirty years and counting: Finding meaning in the N400 component of the event-related brain potentia (ERP). Annual Review of Psychology, 62, 621-647. http://dx.doi.org/ 10.1146/annurev.psych.093008.131123

Kutas, M., \& Hillyard, S. A. (1980). Reading senseless sentences: Brain potentials reflect semantic incongruity. Science, 207, 203-205. http://dx .doi.org/10.1126/science. 7350657

Kutas, M., \& Hillyard, S. A. (1984). Brain potentials during reading reflect word expectancy and semantic association. Nature, 307, 161-163. http:// dx.doi.org/10.1038/307161a0

Kutas, M., Van Petten, C., \& Kluender, R. (2006). Psycholinguistics electrified II (1994-2005). In M. Traxler \& M. A. Gernsbacher (Eds.), Handbook of psycholinguistics (2nd ed., pp. 659-724). London, UK Elsevier. http://dx.doi.org/10.1016/B978-012369374-7/50018-3 
Laszlo, S., \& Federmeier, K. D. (2009). A beautiful day in the neighborhood: An event-related potential study of lexical relationships and prediction in context. Journal of Memory and Language, 61, 326-338. http://dx.doi.org/10.1016/j.jml.2009.06.004

Laszlo, S., \& Federmeier, K. D. (2011). The N400 as a snapshot of interactive processing: Evidence from regression analyses of orthographic neighbor and lexical associate effects. Psychophysiology, 48, 176-186. http://dx.doi.org/10.1111/j.1469-8986.2010.01058.x

Lau, E. F., Phillips, C., \& Poeppel, D. (2008). A cortical network for semantics: (De)constructing the N400. Nature Reviews Neuroscience, 9, 920-933.

Lehtonen, M., Hultén, A., Rodríguez-Fornells, A., Cunillera, T., Tuomainen, J., \& Laine, M. (2012). Differences in word recognition between early bilinguals and monolinguals: Behavioral and ERP evidence. Neuropsychologia, 50, 1362-1371. http://dx.doi.org/10.1016/j .neuropsychologia.2012.02.021

Levy, R. (2008). Expectation-based syntactic comprehension. Cognition, 106, 1126-1177. http://dx.doi.org/10.1016/j.cognition.2007.05.006

Lotze, N., Tune, S., Schlesewsky, M., \& Bornkessel-Schlesewsky, I. (2011). Meaningful physical changes mediate lexical-semantic integration: Top-down and form-based bottom-up information sources interact in the N400. Neuropsychologia, 49, 3573-3582. http://dx.doi.org/ 10.1016/j.neuropsychologia.2011.09.009

Marslen-Wilson, W. D. (1987). Functional parallelism in spoken wordrecognition. Cognition, 25, 71-102. http://dx.doi.org/10.1016/00100277(87)90005-9

McDonald, S. A., \& Shillcock, R. C. (2003). Eye movements reveal the on-line computation of lexical probabilities during reading. Psychological Science, 14, 648-652. http://dx.doi.org/10.1046/j.0956-7976.2003 .psci_1480.x

Miellet, S., Sparrow, L., \& Sereno, S. C. (2007). Word frequency and predictability effects in reading French: An evaluation of the E-Z Reader model. Psychonomic Bulletin \& Review, 14, 762-769. http://dx.doi.org/ 10.3758/BF03196834

Molinaro, N., \& Carreiras, M. (2010). Electrophysiological evidence of interaction between contextual expectation and semantic integration during the processing of collocations. Biological Psychology, 83, 176190. http://dx.doi.org/10.1016/j.biopsycho.2009.12.006

Münte, T. F., Wieringa, B. M., Weyerts, H., Szentkuti, A., Matzke, M., \& Johannes, S. (2001). Differences in brain potentials to open and closed class words: Class and frequency effects. Neuropsychologia, 39, 91102. http://dx.doi.org/10.1016/S0028-3932(00)00095-6

Norris, D. (2006). The Bayesian reader: Explaining word recognition as an optimal Bayesian decision process. Psychological Review, 113, 327357. http://dx.doi.org/10.1037/0033-295X.113.2.327

Oldfield, R. C. (1971). The assessment and analysis of handedness: The Edinburgh inventory. Neuropsychologia, 9, 97-113. http://dx.doi.org/ 10.1016/0028-3932(71)90067-4

Osterhout, L., Bersick, M., \& McKinnon, R. (1997). Brain potentials elicited by words: Word length and frequency predict the latency of an early negativity. Biological Psychology, 46, 143-168. http://dx.doi.org/ 10.1016/S0301-0511(97)05250-2

Paterson, K. B., \& Jordan, T. R. (2010). Effects of increased letter spacing on word identification and eye guidance during reading. Memory \& Cognition, 38, 502-512. http://dx.doi.org/10.3758/MC.38.4.502

Penolazzi, B., Hauk, O., \& Pulvermüller, F. (2007). Early semantic context integration and lexical access as revealed by event-related brain potentials. Biological Psychology, 74, 374-388. http://dx.doi.org/10.1016/j .biopsycho.2006.09.008

Pickering, E. C., \& Schweinberger, S. R. (2003). N200, N250r, and N400 event-related brain potentials reveal three loci of repetition priming for familiar names. Journal of Experimental Psychology: Learning, Memory, and Cognition, 29, 1298-1311. http://dx.doi.org/10.1037/02787393.29.6.1298
Picton, T. W., Bentin, S., Berg, P., Donchin, E., Hillyard, S. A., Johnson, R., Jr, . . Taylor, M. J. (2000). Guidelines for using human event-related potentials to study cognition: Recording standards and publication criteria. Psychophysiology, 37, 127-152. http://dx.doi.org/10.1111/14698986.3720127

Rayner, K., Ashby, J., Pollatsek, A., \& Reichle, E. D. (2004). The effects of frequency and predictability on eye fixations in reading: Implications for the E-Z Reader model. Journal of Experimental Psychology: Human Perception and Performance, 30, 720-732. http://dx.doi.org/10.1037/ 0096-1523.30.4.720

Rayner, K., \& Clifton, C., Jr. (2009). Language processing in reading and speech perception is fast and incremental: Implications for event-related potential research. Biological Psychology, 80, 4-9. http://dx.doi.org/ 10.1016/j.biopsycho.2008.05.002

Rayner, K., \& Duffy, S. A. (1986). Lexical complexity and fixation times in reading: Effects of word frequency, verb complexity, and lexical ambiguity. Memory \& Cognition, 14, 191-201. http://dx.doi.org/ 10.3758/BF03197692

Rayner, K., Reichle, E. D., Stroud, M. J., Williams, C. C., \& Pollatsek, A. (2006). The effect of word frequency, word predictability, and font difficulty on the eye movements of young and older readers. Psychology and Aging, 21, 448-465. http://dx.doi.org/10.1037/0882-7974.21.3.448

Reichle, E. D., \& Drieghe, D. (2013). Using E-Z Reader to examine word skipping during reading. Journal of Experimental Psychology: Learning, Memory, and Cognition, 39, 1311-1320. http://dx.doi.org/10.1037/ a0030910

Reichle, E. D., Pollatsek, A., Fisher, D. L., \& Rayner, K. (1998). Toward a model of eye movement control in reading. Psychological Review, 105 125-157. http://dx.doi.org/10.1037/0033-295X.105.1.125

Reichle, E. D., Rayner, K., \& Pollatsek, A. (2003). The E-Z Reader model of eye-movement control in reading: Comparisons to other models. Behavioral and Brain Sciences, 26, 445-476. http://dx.doi.org/10.1017/ S0140525X03000104

Reichle, E. D., Tokowicz, N., Liu, Y., \& Perfetti, C. A. (2011). Testing an assumption of the E-Z Reader model of eye-movement control during reading: Using event-related potentials to examine the familiarity check. Psychophysiology, 48, 993-1003. http://dx.doi.org/10.1111/j.1469-8986 2011.01169.x

Reingold, E. M., \& Rayner, K. (2006). Examining the word identification stages hypothesized by the E-Z Reader model. Psychological Science, 17, 742-746. http://dx.doi.org/10.1111/j.1467-9280.2006.01775.x

Reingold, E. M., Reichle, E. D., Glaholt, M. G., \& Sheridan, H. (2012). Direct lexical control of eye movements in reading: Evidence from a survival analysis of fixation durations. Cognitive Psychology, 65, 177206. http://dx.doi.org/10.1016/j.cogpsych.2012.03.001

Roehm, D., Bornkessel-Schlesewsky, I., Rösler, F., \& Schlesewsky, M. (2007). To predict or not to predict: Influences of task and strategy on the processing of semantic relations. Journal of Cognitive Neuroscience, 19, 1259-1274. http://dx.doi.org/10.1162/jocn.2007.19.8.1259

Rugg, M. D. (1990). Event-related brain potentials dissociate repetition effects of high- and low-frequency words. Memory \& Cognition, 18, 367-379. http://dx.doi.org/10.3758/BF03197126

Sassenhagen, J., Schlesewsky, M., \& Bornkessel-Schlesewsky, I. (2014). The P600-as-P3 hypothesis revisited: Single-trial analyses reveal that the late EEG positivity following linguistically deviant material is reaction time aligned. Brain and Language, 137, 29-39. http://dx.doi.org/ 10.1016/j.band1.2014.07.010

Sereno, S. C., \& Rayner, K. (2003). Measuring word recognition in reading: Eye movements and event-related potentials. Trends in Cognitive Sciences, 7, 489-493. http://dx.doi.org/10.1016/j.tics.2003.09.010

Sheridan, H., \& Reingold, E. M. (2012). The time course of predictability effects in reading: Evidence from a survival analysis of fixation durations. Visual Cognition, 20, 733-745. http://dx.doi.org/10.1080/ 13506285.2012.693548 
Simola, J., Holmqvist, K., \& Lindgren, M. (2009). Right visual field advantage in parafoveal processing: Evidence from eye-fixation-related potentials. Brain and Language, 111, 101-113. http://dx.doi.org/ 10.1016/j.bandl.2009.08.004

Slattery, T. J., Staub, A., \& Rayner, K. (2012). Saccade launch site as a predictor of fixation durations in reading: Comments on Hand, Miellet, O'Donnell, and Sereno (2010). Journal of Experimental Psychology: Human Perception and Performance, 38, 251-261. http://dx.doi.org/ 10.1037/a0025980

Staub, A. (2011). The effect of lexical predictability on distributions of eye fixation durations. Psychonomic Bulletin \& Review, 18, 371-376. http:// dx.doi.org/10.3758/s13423-010-0046-9

Staub, A., \& Benatar, A. (2013). Individual differences in fixation duration distributions in reading. Psychonomic Bulletin \& Review, 20, 13041311. http://dx.doi.org/10.3758/s13423-013-0444-x

Staub, A., White, S. J., Drieghe, D., Hollway, E. C., \& Rayner, K. (2010). Distributional effects of word frequency on eye fixation durations. Journal of Experimental Psychology: Human Perception and Performance, 36, 1280-1293.

Tune, S., Schlesewsky, M., Small, S. L., Sanford, A. J., Bohan, J., Sassenhagen, J., \& Bornkessel-Schlesewsky, I. (2014). Cross-linguistic variation in the neurophysiological response to semantic processing: Evidence from anomalies at the borderline of awareness. Neuropsychologia, 56, 147-166. http://dx.doi.org/10.1016/j.neuropsychologia.2014 .01 .007

van Berkum, J. J. A., Hagoort, P., \& Brown, C. M. (1999). Semantic integration in sentences and discourse: Evidence from the N400. Journal of Cognitive Neuroscience, 11, 657-671. http://dx.doi.org/10.1162/ 089892999563724

Van Petten, C., Coulson, S., Rubin, S., Plante, E., \& Parks, M. (1999). Time course of word identification and semantic integration in spoken language. Journal of Experimental Psychology: Learning, Memory, and Cognition, 25, 394-417. http://dx.doi.org/10.1037/0278-7393.25.2.394
Van Petten, C., \& Kutas, M. (1990). Interactions between sentence context and word frequency in event-related brain potentials. Memory \& Cognition, 18, 380-393. http://dx.doi.org/10.3758/BF03197127

Van Petten, C., \& Kutas, M. (1991). Influences of semantic and syntactic context on open- and closed-class words. Memory \& Cognition, 19, 95-112. http://dx.doi.org/10.3758/BF03198500

Van Petten, C., Kutas, M., Kluender, R., Mitchiner, M., \& McIsaac, H. (1991). Fractionating the word repetition effect with event-related potentials. Journal of Cognitive Neuroscience, 3, 131-150.

Vegara-Martínez, M., Gómez, P., Jiménez, M., \& Perea, M. (in press). Lexical enhancement during prime-target integration: ERP evidence from matched-case identity priming. Cognitive, Affective \& Behavioral Neuroscience.

Vissers, C. T. W. M., Chwilla, D. J., \& Kolk, H. H. J. (2006). Monitoring in language perception: The effect of misspellings of words in highly constrained sentences. Brain Research, 1106, 150-163. http://dx.doi org/10.1016/j.brainres.2006.05.012

White, S. J., \& Staub, A. (2012). The distribution of fixation durations during reading: Effects of stimulus quality. Journal of Experimental Psychology: Human Perception and Performance, 38, 603-617. http:// dx.doi.org/10.1037/a0025338

Whitford, V., \& Titone, D. (2014). The effects of reading comprehension and launch site on frequency-predictability interactions during paragraph reading. The Quarterly Journal of Experimental Psychology, 67, 11511165. http://dx.doi.org/10.1080/17470218.2013.848216

Zwitserlood, P. (1989). The locus of the effects of sentential-semantic context in spoken-word processing. Cognition, 32, 25-64. http://dx.doi .org/10.1016/0010-0277(89)90013-9 